\title{
Trend Analysis of Technologies Supporting the Availability of Online Content: From Keyword- Based Search to the Semantic Web ${ }^{1}$
}

\author{
Tünde LENGYEL MOLNÁR \\ Eszterházy Károly University \\ Eger, Hungary \\ e-mail: lengyelne.tunde@uni-eszterhazy.hu
}

\begin{abstract}
The era of Web 1.0 implied the connection of web-based documents via links, which enabled search engines to scan for information and guarantee the search and availability of webpages. Web 2.0 represented the next evolutionary stage. Known as the collaborative web, the emphasis in this case was on the establishment of services and content by the community. Search options were complemented with labelling and frequently undesirable clickstream analysis coupled with push technology-supported information provision. The semantic web is a revolutionary development, which, in addition to processing information by humans, assures the readability of datasets by machines and facilitates communication between devices. In order to promote data and information processing by machines, the semantic web relies on a special ontology allocating the respective meaning to the given data along with relying on the global indexing and naming schemes of the web. Several ontologies emerged with differing basic guidelines while displaying compatibility to the RDF standard ranging from the more semantic description of bibliographical data in libraries to the description of information gained from social networks and human conversations. While Web 3.0 is often used interchangeably with the semantic web, the former one with its intelligent server function exceeds the semantic web. We have to ask ourselves, however, whether we can rely on the accuracy of the obtained data, and we must explore what progress have libraries - expected to increase reliability - made regarding the implementation of semantic data storage.
\end{abstract}

Keywords: semantic web, Web 2.0, Web 3.0, LRM, Library Reference Model, RDF, search systems, semantic search

1 This paper was supported by János Bolyai Research Scholarship of the Hungarian Academy of Sciences. 


\section{Introduction}

The Fourth Industrial Revolution radically impacted communication forms. While psychologists switched their focus to the impact of our presence in online communities from that of long hours of television watching, technological developments reached the next level. Accordingly, artificial intelligence has penetrated everyday life, including the communication process, as chatbots provide services in web stores and avatars process our requests on the search pages of libraries. Thus, not only is communication placed on an on-line basis, but one party in the communication chain has become either a robot or an algorithm. It was less than forty years ago when the forwarding option of hypertext materials emerged, and today if we want to provide information to a specific audience it is not enough to establish suitable content as we need to be familiar with technologies facilitating the retrieval of the given information. Furthermore, a few years ago, it was sufficient to place appropriate keywords among the metadata of our websites, but today we can establish semantic connections between the given data. This helps us to exceed the establishment of connections between the given pages and to reach Web 3.0. My study provides an overview of the formation of the semantic web along with introducing the basic guidelines of its operation. I will explore the trends of the respective processes in order to highlight the need for information storage and retrieval, along with introducing the options provided by the semantic web. I will illustrate that several ontologies appeared showing compatibility to the RDF standard with completely different guidelines ranging from a more semantic description of bibliographical data in libraries to the description of information gained from social networks and human communication. Where are we now in this process? How can we describe Web 3.0? Can we trust the authenticity of the data obtained? Have libraries - expected to increase the reliability of information - started to implement semantic data storage?

As a result of the technological development, the application of algorithms facilitating full text search had become widespread by the second half of the 1990s. Keyword-based full text search options appeared after the discovery of hypertext-based information search during which the web content was mapped via the keywords marked as links. Another previous development included the use of a scanning language to gain access to the structured data of texts stored in databases, which enabled the selection of the potential data for search but had no impact on the given process (Lengyelné Molnár, 2014). Keyword-based search explores the syntactically identical elements but ignores the semantic ties. 


\section{The Era of the Semantic Web}

By the second half of the first decade of the $21^{\text {st }}$ century, the emphasis was placed on this deficiency, and the semantic web was seen as a key for access to electronically stored data. The semantic web is "a global network metadata infrastructure facilitating the integration of data available on the World Wide Web, the definition and description of the respective connections and the interpretation of the given data. Such developments will lead to the formation of the generation of the new global network, the extension of the current web, known as Web 3.0" (Fülöp, 2018). In order to comprehend this definition, we need to retrace the road taken until now.

Following the emergence of the World Wide Web, we shared pages connected with links. This presented a global document repository for the users, who were helped by portals in accessing the given webpages to be superseded by search websites utilizing search engines. Search engines explore the given webpages via indexing the keywords in the text or the metadata with the abovementioned method. At the time of Web 1.0, this support was sufficient as users could reach the respective pages by clicking and interpret or explore the information on the given webpage independently. In the second decade of the World Wide Web, after 2005, the content was not produced by the manager or owner of the given website as the community itself became a content producer. While Web 1.0 was characterized by static content, in the case of Web 2.0, the community producing the given content used a framework provided by the producers of the webpage, which resulted in a more dynamic appearance and continuous growth facilitating the modification and change of the respective data. Web 2.0 is "a surface of the World Wide Web facilitating high-level interaction determined by the social media, a web segment including special community-produced sites, picture and video sharing platforms, blogs, vlogs, and other surfaces" (Szúts, 2018). Web 2.0 using previously existing technology in a new way did not bring major changes in accessibility to the content of web pages, and Web 3.0 is expected to implement the concept of the fully restructured web (Krauth-Kömlődi, 2008). The latest achievements included the continuous expansion of algorithms operating search engines, and, in addition to full text search, the whole content of the given website was disclosed, content in .pdf was indexed, and significant advances were made in the retrieval of nontextual content. However, semantic connections were not revealed, and still a large segment of the web unreachable by search engines, named the Deep Web, remained unknown. This included the content of library catalogues containing very thorough bibliographical descriptions with more detailed metadata but with no connections or compatibility with the standards of the semantic web. For this reason, they remain invisible for the search engines. Furthermore, it was still the user who processed the content of the webpages appearing as a result of searching for hits. 
The solution came from two directions:

Library profession experts have already started "to separate essential units with special importance for users, thus requiring the presentation of information. These crucial concept categories were described in abstract form as entities" (Hubay, 2019a) at the Stockholm Bibliographical Records Seminar in 1990. Accordingly, 10 entities were divided into three groups. Entities expressing the result of a creative effort include the work, form of expression, presentation form, and copy. Entities referring to the creator of the work are person and body or organization, and the third entity category included the object of the production effort, namely concept, object, event, and place (IFLA, 1998).

During the analysis of the entities, a work commission "determines the characteristic features and attributes of the given entities along with the connections that have special importance for the user during the bibliographical search. It also interprets the answers received for the search request and navigates in the universe of entities described by bibliographical records." The entities can be divided into two large groups: attributes related to physical appearance and identifiers pertaining to the content of the given work (catalogue number, content identifiers). These connections form the basis of the model (i.e. a PERSON "created this:" WORK). The entities, attributes, and connections are described in a hierarchical structure or order (Pat et al., 2017).

Practical applications, however, revealed that the models describing the functional requirements must be combined due to the respective discrepancies, and a uniform model has to be created. The FRBR Review Group started this work in 2010, and in 2013 they formed the Consolidation Editorial Group (CEG). The manuscript was submitted for review in 2016, and it was approved by the IFLA Standardization Committee in August 2017 (Pat et al., 2017). Accordingly, "the three models were integrated into a uniform consolidated system via the elimination of the respective inconsistencies resulting in the formation of the Library Reference Model” (Hubay, 2019b).

\section{Library Reference Model}

Utilizing the FRBR methodology, the LRM includes the entity analysis, the separation of the most important documents for the users, the identification of the entities, and the attributes of the respective connections as the most significant considerations for the search. The aim of the model - similarly to the FRBR is the establishment of basic guidelines without making preliminary statements regarding data storage (Dancs, 2018).

The LRM model prioritizes the following aspects: the work, form of expression, form of appearance, and structural connections between the given entities. The 
model focusing on the tasks of users takes into consideration the widespread use of bibliographical and authority-related data along with the needs of the respective users. The five tasks users were expected to perform: location, identification, selection, accession, and investigation of data were described in a general sense and without a sequential order (Pat et al., 2017). The entity linkage model includes the following components: entities, attributes, and connections.

- Entities: categories in the focus of interest (determine the frame of the model and function as nodes).

- Attributes: data describing the occurrence of entities; provide information on entities while they are dependent on them.

- Connections, correlations: attributes connecting and describing the entities.

The hierarchical system of entities, attributes, and connections was retained in the LRM. 10 entities are allocated under one upper hierarchy level, known as the Res ("any entity of the given universe under discussion"), in the following way (Pat et al., 2017).

Table 1. The hierarchy of entities

Entity Hierarchy

Top Level

Second Level

Third Level

\begin{tabular}{ll}
\hline LRM-E1 Res & \\
\hline & LRM-E2 Work \\
& LRM-E3 Expression \\
\hline & LRM-E4 Manifestation \\
\hline & LRM-E5 Item \\
\hline LRM-E6 Agent & \\
\hline- & LRM-E7 Person \\
\hline- & LRM-E8 Collective Agent \\
\hline \multicolumn{2}{l}{ LRM-E9 Nomen } \\
\hline \multicolumn{2}{l}{ LRM-E10 Place } \\
\hline
\end{tabular}

The LRM model not only facilitates transparency and compatibility between library systems (as currently used standards, including the /MARC/, meet this requirement), but its introduction implying a shift towards RDF-structured descriptions (as all the entities could be described in one structure or within one graph) results in the reduction of the size of the Deep Web, the segment invisible and unreachable for search engines. In the LRM, the data of entities are separated and complemented with recorded connection fields and references, making them 
visible or perceivable for the search engines. ${ }^{2}$ It is also important that users are provided much higher-standard library services, while the respective data is enhanced since the semantic description of the documents enables the on-line catalogue system to provide more detailed information besides the bibliographical descriptions. Libraries and public collections relying on the semantic web at its current stage of development can provide higher-level services for users by presenting the semantic connections with the respective hits pertaining to exhibitions, events, and education materials. The search surface of PLM enables the user to express such interest concerning the given hits.

\section{1 eerorimerearmustum EXHIBITIONS EVENTS MUSEUM LEARNING}

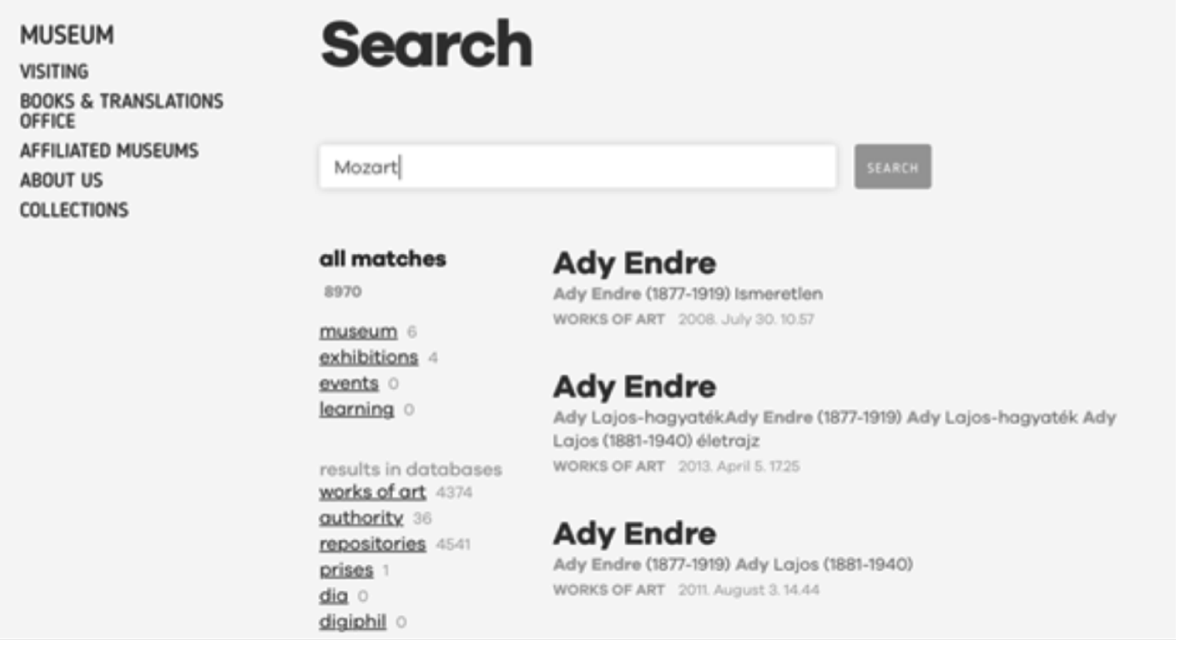

Figure 1. The webpage of PLM (Petófi Literary Museum)

Libraries, however, have not yet implemented the LRM model. Researchers at the University of Wisconsin (Park-Kipp, 2019) pointed out that libraries in the USA and other parts of the world are currently developing their LLD schemes, but they do not utilize ontologies based on LRM models. With the exception of the Library of Congress, libraries prefer to use the schemes, ontologies, and data models of the Linked Data.

2 In order to be used by search engines, the data do not have to be in RDF format as several discovery software inherently include this option. Accordingly, the data components are labelled with an HTML page code presenting the given data component as an address, information about length, or a potential contributor. Webpages enhanced with semantic markers (semantic for its capability to interpret the given data) are intelligible for search algorithms and can be indexed as well. This is a necessary yet not a sufficient condition for access into the search engine. 


\section{Linked Data: Data Connections}

Linked Data is the result of a data-centric perspective dominant in the post-2010 period. ${ }^{3}$ It utilizes the basic operational concept of the web, but instead of sharing documents it facilitates the sharing of structured data on a global level. Just like the web, it relies on links while utilizing the principle of the four connected or linked data (Bizer et al., 2018):

1. Use of URIs (uniform resource identifiers) for identifying the units; the URI guarantees the uniform naming of the entity.

2. Search should be performed with HTTP URI, while a hypertext transmission protocol assures access to the description of entities.

3. The URI search should be based on standardized information (RDF, OWL, SKOS, SPARQL, etc.). The two entities published by the various data sources are connected to the resource description framework (RDF) via unifying data model references. The Linked Data applications follow the RDF references via searching for URIs identifying the entities with the HTTP protocol.

4. The linked data should provide references to other URIs in order to discover more information. When the server responds with an RDF description during the search for an entity, the resulting hit can contain more references, making it suitable for identifying more data sources.

\section{RDF - Resource Description Framework}

The concept of the RDF is indispensable for the semantic web as it is a standardized model of data exchange taking place on the Internet. According to a W3C definition, it is a framework which facilitates the description of information on the web.

The RDF is a declarative language including triplets, which are a combination of a subject, object, and a predicate describing everything as a simple declarative sentence. Furthermore, the correlation between the subject and object is determined by the predicate. The set of triplets forms the RDF graph, in which all triplets are represented by a "node-edge-node connection" (W3C, 2004). The composition of a statement is helped by a formal vocabulary known as the RDF Schema (RDFS, RDF-VOCABULARY). We present a specific example below:

$\begin{array}{lll}\text { Einstein } & \text { works as } & \text { a physicist. } \\ \text { Subject } & \text { Predicate } & \text { Object }\end{array}$

3 The $1^{\text {st }}$ International Workshop on Consuming Linked Data was organized in 2010, but the concept of the Linked Data has been in use since 2006. 
The RDF designed as a foundation for other languages functions as a standard. At the same time, the schemes forming its foundation can differ (Király-Szekely, 2018), and the RDF can even support the chronological development of the schemes.

\section{The Most Often Used Schemes in LLD and the Semantic Web}

Dublin Core (DC) (Dublin Core ${ }^{\mathrm{TM}}$ Metadata Initiative): This metadata system capable of describing 15 attributes was established in 1995 and reached its present capacity as a result of continuously being updated and adjusted to the requirements of the National Information Standards Organization of the United States. The components describing the 15 metadata are complemented by an attribute, class, data type, and vocabulary coding scheme to form the Dublin Core expressions together (DCMI, Dublin Core Metadata Terms). It is a highly prevalent and propagated metadata description scheme, and its application in library systems guarantees the connection with the semantic web.

$B I B O$ (The Bibliographic Ontology): It is a bibliographical ontology used in library environments for citation, document qualification, and document description. The bibliographical ontology is not a standard but a specification built on the rule facilitating the formation of the RDF (Bruce, 2009). It is based on the hierarchical description of connection types - all important relations are identified by an URI, and the hierarchical structure allows the performance of logical operations. "If the ISBN of X is Y, then $\mathrm{Y}$ is the identifier of $\mathrm{X}$ as well." One setback of the BIBO is the lack of several concepts in its web scheme.

FOAF (Friend of a Friend): The purpose of the FOAF project is the establishment of connection between people and information on the Internet. It is built on the idea that not only data in documents can be described but those in the heads of people as well. It was prepared for a social network, and, based upon the cooperation, friendships, and social networks of people, it creates connections with the respective data. It is a computer language determining the vocabulary of human connections and is usable in a structured form. It is used by semantic web applications for the description of humans and their relations.

SKOS (Simple Knowledge Organization System): The SKOS is a general data model for the sharing and linking of knowledge organization systems with the help of the semantic web (W3C, 2009).

Schema.org: The Schema.org structured data-marking dictionary established by Google, Microsoft, Yahoo!, and Yandex enables webmasters to embed metadata on HTML5 webpages via micro-data labels recognized by the search engines of Google, Yahoo!, and Microsoft Bing. The Online Computer Library Centre 
(OCLC) uses, among others, Schema.org for facilitating a connection with the Linked Data model. This makes its data pool more accessible for the previously mentioned three search engines. It is a rather popular scheme as the dictionaries of the Schema.org are developed continuously by an open public community effort, and "several applications ranging from Google through Microsoft and Pinterest to Yandex and others rely on these vocabularies for the enhancement and expanding and intensification of experiences".

\section{Web 3.0}

In sum, while web documents are connected with links facilitating accessibility and searchability, the next stage of the evolution of the web is the semantic web including datasets readable by machines. In order to promote data processing by machines, the semantic web allocates the respective meaning to the given data by a special ontology in addition to the global indexing and naming schemes of the web. The idea of the semantic web can be considered realized if a meaning related to a given document is as thorough as or even more detailed than that of provided by the human brain.

What is the difference between the semantic web and Web 3.0? "Web 3.0 is an intelligent offering of a data network consisting of a collection of structured data records published in the web in repeatedly reusable formats (e.g., XML, RDF)” (Isaias, 2012). Frequently, the semantic web and Web 3.0 are used as interchangeable concepts. This is not without any justification as the aim of Web 3.0 is substituting people with software agents and improving the efficiency of the collection, transmission, and analysis of data on the web. Such features suggest a similarity with the definition of the semantic web as the latter is a technology facilitating the sharing of machine-readable data by the use of metadata schemes and ontology while matching the data with the respective meaning. The main difference is represented by the Web 3.0 intelligent server system as its application can produce a complete itinerary (Ashir, 2018; Park-Kipp, 2019).

Web 2.0 is often referred to as the web of collaboration due to its emphasis on services, content creation, and the sharing of knowledge components. We describe a few of its most popular services (Racskó, 2011):

- Unified entry systems (OpenID): A user name-password dyad facilitating simple entry, which can be used in many locations by the person applying it.

- Documents based on cooperation (i.e. Google documents): In the second decade of the $21^{\text {st }}$ century, services based on cooperation and shared work become popular, enabling more than one person to work on a document or product in real time without the need for software or storage space. 
- Professional communities based on shared interest (Ning): It implies a community-forming capability based on professional interest. This service appears in the social media.

- Forums: for the shared discussion of problems and the respective options. One specific example is the professional forum.

- News channels.

- Social media.

- Community bookmarks.

- Book recommendation and evaluation services.

- On-line map services.

- Content sharing services.

- Wikipedia and wiki services.

- Mashups: websites embedding other applications.

- Picture and video sharing services, etc.

One of the greatest deficiencies of Web 2.0 was that only those people could take advantage of the otherwise excellent support services who had a level of digital literacy sufficient to use the given systems, websites, and services.

Another disadvantage was that as a result of labelling and continuous data analysis the system stored a high amount of information about the users without their knowledge. The clickstream, or analysis of people's clicking habits, provides a sophisticated and more thorough picture or image than a simple reference or citation management tool. This option is frequently used by disseminators of unwanted ads and recommendations based on the profile analysis of the user and screening the respective data locations and hits.

Web 3.0 is, however, an easy-to-use and more secure system. Since the given data are described in the perspective of a graph, the features include not only click analysis but the data storage is complemented with linkage-related information.

The operation of Web 3.0 is determined by the following systems/processes:

Big Data: Analysis of a high amount of data. "The more we communicate, perform transactions, and exchange information, the greater the Big Data becomes, enhancing the cumulative meaning of the dataset" (Findlay, 2015).

Cognitive learning by machine: The computer collects previously unstructured data - pictures, videos, sounds, and languages - and links them with cognitive metadata in a computation model resulting in semantic improvement. (With time, these systems are expected to become more accurate and reliable).

Data mining: Data mining has reached a developmental level when communication in social media is analysed not only by texts but via face recognition systems. "The more information a user provides, the more they are rewarded with a richer, more dynamic experience" (Findlay, 2015).

Artificial intelligence based on computational manoeuvres can make decisions instead of humans as the system not only designs the shortest trip towards our 
destination but books accommodation, and if this type of development reaches its highest potential it can navigate our self-driving car.

Internet of Things: This is a definitive component of Web 3.0 as it provides a perfect example for communication among machines. Home appliances with Internet connection make decisions instead of people: for example, ordering food in low supply in the refrigerator. Personal assistants following our orders, regulating room temperature and lighting, providing cooking advice, preparing a shopping list, and even carrying on a conversation belong to this category as well.

Virtual and augmented reality: Studies on the operation of Web 3.0 highlight the capability of three-dimensional images to increase user experience and improve the quality and enjoyment value of the given services.

Accessibility: While previously different data formats hindered communication, this disappears in the world of Web 3.0 as not only such obstacles are eliminated, but accessibility is assured between devices (refrigerator, computer, car), resulting in the perfect user experience (Aslam-Sonkar, 2019).

\section{Search Systems}

A semantic search system will ask the user to identify the given meaning of the word; thus, if we enter the word "jaguar", the machine wants to know whether we want information related to the automobile or the animal.

\section{WolframAlpha}

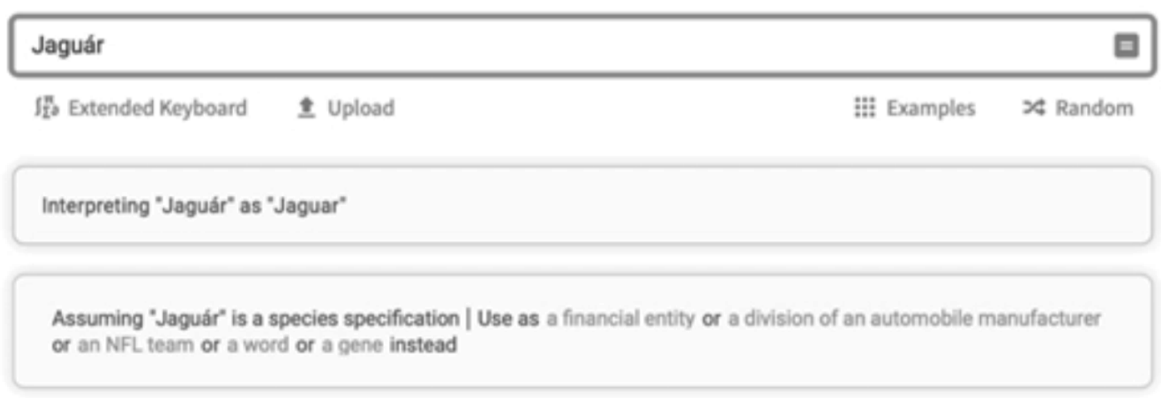

Figure 2. Search in WolframAlpha interface

While the search platforms of libraries provide good examples, this option is not fully realized. One of the vanguards, the National Library of France (Bibliothèque nationale de France, $B n F$ ), offers search platforms which ask the user to make their search more accurate as shown below in the case of the term "jaguar". 


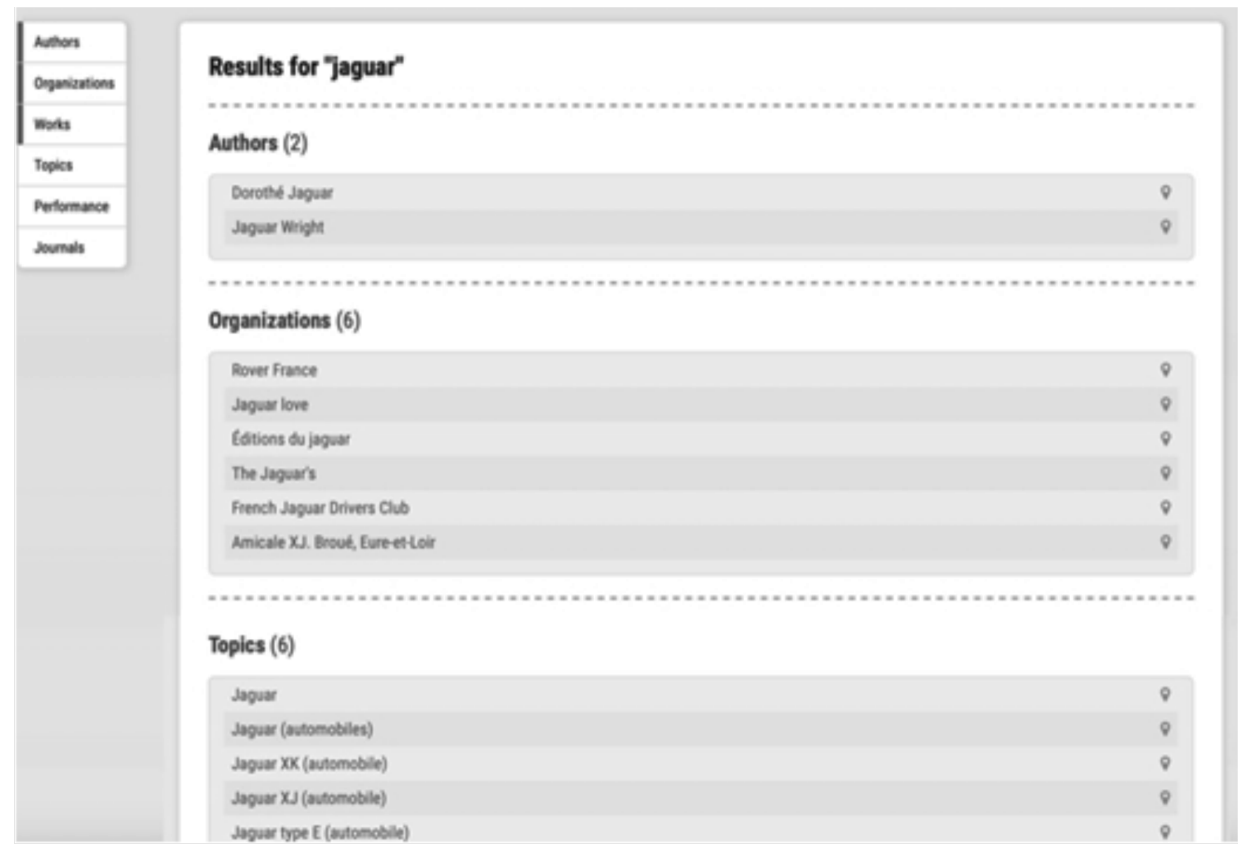

Figure 3. The search page of the Bibliothèque nationale de France

The development process has to reach a level that in case of searching for an item in a library catalogue the following information is revealed: other users' view pertaining to the item, the availability of a review, or a theatrical or musical version. Furthermore, we can provide merchandizing-related information if the given webshops use the protocols of the semantic web. Presently, this level of development is subject of isolated research efforts, but the process has already started. The OCLC operates an entitlement service (viaf.org) where the joined institutions share their bibliographical and entitlement records, enabling national and other connected libraries to assist each other's work. In the case of integrated library systems, the development effort has started, while many institutions are reluctant to open up their records. The start of the development process is indicated by a demo version (i.e. Exlibris MetaLib) or introductory efforts (i.e. Qulto Connect).

\section{Reliability}

The shifting of library standards to meet the requirements of the semantic web facilitates the transmission of reliable information and strengthens the future roles of libraries. The most important impact of the semantic web is that web data are interpreted, categorized, and processed by machines, leading to the autonomous 
integration of data and services. One such example is sharing information on the web portal of our institution with people who can share it further, make comments, or create links with other subjects. If we integrate this ontology into the operation of our portal, then the respective content will be complemented with new terminology, including "news, publication, author, institution" along with such definitions as "all news is a publication, all authors of publications are persons", which will lead to much more accurate and reliable hits than before (Vidács, 2015). We can also find out the institutional affiliation of the given author, which could be previously done only by databases built by humans. While the semantic web provides unlimited options, we must keep in mind the dangers of unauthorized access or manipulative use. Thus, it is essential that reliable institutions and libraries join the world of the semantic web as soon as possible.

Institutions are slow to recognize the necessity of the semantic web, but the provision of accurate and rich data content and high-quality services to people are crucial for the future, especially since the semantic web is a key to the development of on-line environments. Appropriate use requires familiarity with the options provided by Web 3.0, and proper knowledge of the background of the given process is a guarantee of reliability.

\section{References}

Ashir, A. (2018). Communication Process of Disaster Management: Shift from Web 2.0 to Web 3.0. In: Zhi, L.-Kaoru, O. (eds.), Smart Technologies for Emergency Response and Disaster Management. Hershey, PA, USA: IGI Global.

Aslam, S.-Sonkar, S. K. (2019). Journey of Web 2.0 to Web 3.o.

Bizer, C.-Vidal, M.-E.-Skaf-Molli, H. (2018). Linked Open Data. In: Liu, L.-Özsu, M. T. (eds.), Encyclopedia of Database Systems. New York, NY: Springer New York.

D’Arcus, B.-Giasson, F. (2009). Bibliographic Ontology Specification [Online]. Available at: <http://bibliontology.com> (accessed on: 17 July 2020).

Dancs, S. (2018). „RDA reborn” - a könyvtári referenciamodell és az átalakuló RDA - 1. rész: Bevezetés az IFLA LRM-be ["RDA Reborn" - The Library Reference Model and RDA in Transformation. Part 1: Introduction to the IFLA LRM]. Tudományos es Múszaki Tájékoztatás 65: 141-152.

Findlay, V. (2015). Security and Privacy Issues of Web 3.0.

FOAF, 2000-2015+ [Online]. Available at: <http://www.foaf-project.org> (accessed on: 17 July 2020).

FOAF, 2014. Vocabulary Specification [Online]. Available at: <http://xmlns.com/ foaf/spec/> (accessed on: 17 July 2020). 
Fülöp, E. (2018). A szemantikus háló két fogalma, a katalógusok új generációja és a könyvtárak szerepe [The Two Concepts of the Semantic Web, the New Generation of Catalogues and the Role of Libraries]. Tudományos es Múszaki Tájékoztatás 65: 401-408.

Hubay, M. (2019). Tények, mítoszok és lehetőségek a szemantikus web világában [Facts, Myths, and Options in the World of the Semantic Web]. Library Review/ Könyvtári Figyeló 65(2): 245-253.

(2020). Adatgazdagítás, adatszolgáltatás és discovery hagyományos és szemantikus metaadat-környezetben [Data Reconciliation, Data Provision, and Discovery in a Traditional and Semantic Metadata Environment]. Tudományos es Múszaki Tájékoztatás 67: 291-300.

IFLA, 1998. Functional Requirements for Bibliographic Records. Final Report. Munich: K.G. Saur.

Isaias, P. (2012). Towards Learning and Instruction in Web 3.0: Advances in Cognitive and Educational Psychology. New York, NY: Springer.

Király, S.-Szekely, Sz. (2018). Analysing RPC and Testing the Performance of Solutions. Informatica (Ljubljana) 42: 551-561.

Krauth, P.-Kömlődi, F. (2008). A Web 2.0 jelenség (és ami mögötte van) [The Web 2.0 Phenomenon (and Its Background)]. In: Dömölki, Bálint (ed.), Égen-földön informatika. Budapest: Typotex Kiadó, 631-660.

Lengyelné Molnár, T. (2014). Kulcsszó-meghatározási technikák [Keyword Definition Techniques]. Tudományos és Múszaki Tájékoztatás 61: 378-385.

Park, H.-Kipp, M. (2019). Library Linked Data Models: Library Data in the Semantic Web. Cataloging \& Classification Quarterly 57: 261-277.

Pat, R.-Patrick, L. B.-Maja, Z. U. (2017). IFLA könyvtári referenciamodell. A bibliográfiai információk elméleti modellje [The IFLA Library Reference Model. The Theoretical Model of Bibliographic Information]. Netherlands: The International Federation of Library Associations and Institutions (IFLA).

Racskó, R. (2011). Virtuális könyvtárak [Virtual Libraries]. Eger: EKF Líceum.

Szúts, Z. (2018). Online: Az internetes kommunikáció és média története, elmélete és jelenségei. [Online: The History, Theoretical Background, and Main Phenomena of Internet-Based Communication and Media]. Budapest: Wolters Kluwer.

Vidács, A. (2015). Web 3.0. Szemantikus web [Online]. Available at: <http:// www.tmit.bme.hu/sites/default/files/2015-10-13-vitmma04.pdf> (accessed on: 17 July 2020).

W3C, 2004. Resource Description Framework (RDF): Concepts and Abstract Syntax [Online]. Available at: <https://www.w3.org/TR/2004/REC-rdfconcepts-20040210/> (accessed on: 17 July 2020). 
W3C, 2009. SKOS Simple Knowledge Organization System Namespace Document [Online]. Available at: <https://www.w3.org/2009/08/skos-reference/skos. html\#> (accessed on: 17 July 2020).

\section{Cite as:}

Molnár Lengyel, T. (2020). Trend Analysis of Technologies Supporting the Availability of Online Content: From Keyword-Based Search to the Semantic Web. Acta Universitatis Sapientae, Communicatio 7: 92-106. DOI: 10.2478/ auscom-2020-0007. 